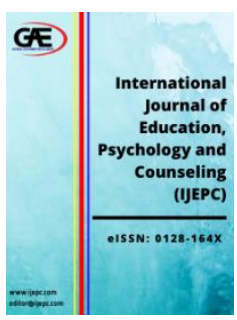

INTERNATIONAL JOURNAL OF EDUCATION, PSYCHOLOGY AND COUNSELLING (IJEPC)

www.ijepc.com

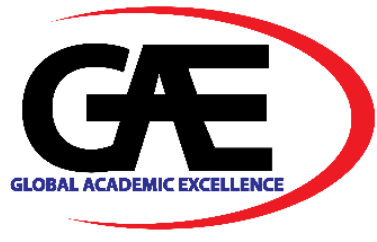

\title{
ANALYSING THE PRE-COMPETITION ANXIETY AMONG BASKETBALL PLAYERS UNDER EIGHTEEN BASED ON THEIR POSITIONS
}

\author{
Yaw Teck Hing ${ }^{1 *}$, Pathmanathan A/L Suppiah ${ }^{2}$, Hasnol Noordin ${ }^{3}$ \\ 1 Faculty Psychology \& Education, Universiti Malaysia Sabah (UMS), Malaysia \\ Email: dp1811030t@student.ums.edu.my \\ 2 Faculty Psychology \& Education, Universiti Malaysia Sabah (UMS), Malaysia \\ Email: pathmaha@ums.edu.my \\ 3 Faculty Psychology \& Education, Universiti Malaysia Sabah (UMS), Malaysia \\ Email: ndhasnol@ums.edu.my \\ Corresponding Author
}

\section{Article Info:}

\section{Article history:}

Received date: 11.08 .2021

Revised date: 15.08 .2021

Accepted date: 22.08 .2021

Published date: 05.09.2021

\section{To cite this document:}

Yaw, T. H., Suppiah, P., \& Noordin, H. (2021). Analysing The PreCompetition Anxiety Among Basketball Players Under Eighteen Based On Their Positions. International Journal of Education, Psychology and Counselling, 6 (42), 289-298.

DOI: $10.35631 / \mathrm{IJEPC} .642024$.

This work is licensed under CC BY 4.0

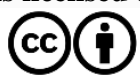

Abstract:

Psychological factors are some of the factors influencing a player's achievement in basketball tournaments. A survey study was conducted to compare the pre-competition anxiety level based on the players' positioning among 144 male basketball players who are under 18 years old in Sabah. The Competitive State Anxiety Inventory-2 (CSAI-2) which was translated into the Malay language was used as the main instrument in this study along with the Kruskal-Wallis Test. The findings indicated that there is no significant difference in the pre-competition anxiety level among the players based on their positioning $\chi 2(2)=3.742, p=.154(p>.05)$. The findings of the cognitive anxiety subscale also were found to be insignificant based on the positioning; $\chi 2(2)=1.938, p=.380(p>.05)$. The somatic anxiety of the pre-competition findings also showed no difference based on the positions of players; $\chi 2(2)=$ $1.509, \mathrm{p}=.470(\mathrm{p}>.05)$. Moreover, the values for subscale of confidence was also found to be insignificant; $\chi 2(2)=1.565, \mathrm{p}=.457$ ( $\mathrm{p}>.05)$. Therefore, the study found out that the environmental factors play a crucial role in reducing the basketball players' pre-competition anxiety. The coaches and trainers should consider these environmental factors in improving their players' precompetition anxiety, thus allowing them to compete and perform at their best state of mind.

Keywords:

Pre-Competition Anxiety, Basketball, Kruskal-Wallis Test 


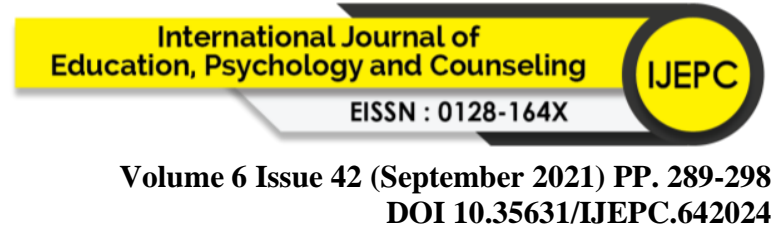

\section{Introduction}

The success of a player in a basketball game is often associated with psychological factors including the intrinsic factors, fitness and skills in the game (Smith \& Smoll, 1990). The intrinsic factor is one of the determining factors of achieving success and personal best in basketball (Sighinolfi, 2020). Previous studies showed that the anxiety level at the precompetition in a basketball tournament could either aid a player to achieve his personal best or lead to his downfall (He et. al., 2011; Mulvenna et. al., 2020). This was further supported by Robazza et. al. (2012) and Vila et. al., (2020), in which they stated that the best achievement in the basketball game is influenced by the ability and strength of the players in managing their anxiety. Therefore, it is crucial to identify the pre-competition anxiety factors so the players could prepare themselves better with controllable pre-competition anxiety levels hence achieve success in the game.

Some of the psychological factors perceived to be influencing the athletes' performance in sports include pre-competition anxiety. This can be further divided into three subscales' cognitive anxiety, somatic anxiety and self-confidence (Martens et. al., 1990). The coach or trainer must acknowledge and keep track of the players' pre-competition anxiety level, specifically in the basketball sport, so they could be well prepared to win the game. Basketball players are put into three main positions; centre, forward and guard (Sekulic et. al., 2017). Each position has its role to be played in the game. Forward players and guards are subjected to the play at the front while the centre players manage at the back (Anne Delextrat, 2004). It is believed that the basketball game pattern based on the players' positioning would influence their pre-competition anxiety including the three subscales; cognitive anxiety, somatic anxiety and self-confidence. Therefore, this research was conducted to identify the level of precompetition anxiety in terms of cognitive anxiety, somatic anxiety, and self-confidence in the basketball sport so it could be a guidance for the coaches and trainers out there in preparing periodization according to the athletes' needs and positions.

\section{Methodology}

\section{Research Design}

This research was conducted based on a quantitative research design with a survey method. The survey method is a popular non-experimental research method in the various field especially in social science (Chua, 2006). The survey method was implemented in this research with a questionnaire as the main instrument.

\section{Instrument}

The instrument used in this research was The Competitive State Anxiety Inventory-2 (CSAI2) which was developed by Martens et. al., (1990) consisting of three subscales to measure cognitive anxiety, somatic anxiety and self-confidence. It was translated into the Malay language by Aris Fazil $\mathrm{Hj}$ Ujang (2005) with a reliability of 0.81 . A total of 27 items were used as the measurement of pre-competition anxiety level with 4 Likert-scale values ( 1 - Never, 2 - Sometimes, 3 - Frequently, 4 - Always).

\section{Research Procedure}

The research proposal was first approved by the Faculty of Psychology and Education, UMS (UMS/Fpp6.4/600-2/7). Then, the parents and guardians of the players were approached to obtain their permission before starting the research with the players. The basketball players 


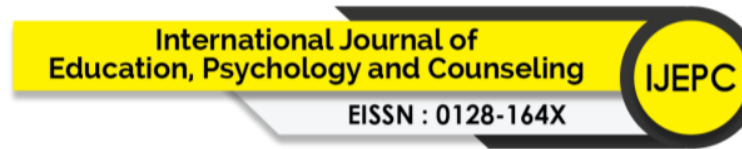

Volume 6 Issue 42 (September 2021) PP. 289-298 DOI 10.35631/IJEPC.642024

were put into three different groups based on their roles and positions during the basketball tournament for Sabah Sports School Championship, which was held from $3^{\text {rd }}$ until $7^{\text {th }}$ February 2020. The Competitive State Anxiety Inventory-2 (CSAI-2) was distributed one hour before the competition began. This was at par with the research conducted by Radzi, Yusuf, Amir, \& Mansor (2018) and to ensure that the data obtained are accurate and relevant to the Multidimensional Theory (Cox, 2002).

\section{Research Sample}

The research was conducted with 144 male basketball players who are under 18 years old. They could be classified into 49 guards, 49 forward players and 46 centre players. All these players participated in the Sabah Sports Schools Championship from $3^{\text {rd }}$ until $7^{\text {th }}$ February 2020.

\section{Data Analysis}

The data was analysed and interpreted statistically using IBM SPSS Statistic Version 25.0 software. Kruskal-Wallis Test was also conducted to identify the difference between precompetition anxiety and subscales (cognitive, somatic and self-confidence) among the male players based on their positions in their teams.

\section{Research Findings}

Table 1: Number of Male Basketball Players Based on Their Positions

\begin{tabular}{ccc}
\hline Position & Number of Players & Percentage (\%) \\
\hline Guard & 49 & 34 \\
Forward & 49 & 34 \\
Centre & 46 & 32 \\
Total & 144 & 100 \\
\hline
\end{tabular}

The reliability test conducted showed that the alpha value for CSAI- 2 Test is $r=0.709$. The subscale of cognitive anxiety recorded $r=0.631$, somatic anxiety recorded $r=0.629$, and selfconfidence value was $\mathrm{r}=0.850$.

Table 2: Normality Test (Kolmogorov-Smirnov ${ }^{a}$ ) for the Competitive State Anxiety Inventory-2 (CSAI-2) and Subscales of Cognitive Anxiety, Somatic Anxiety and SelfConfidence

\begin{tabular}{lccc}
\hline \multicolumn{4}{c}{ Tests of Normality } \\
\multicolumn{1}{c}{ Kolmogorov-Smirnov ${ }^{\boldsymbol{a}}$} & & \\
& Statistic & $\boldsymbol{d f}$ & Sig. \\
The Competitive State Anxiety Inventory- & .169 & 144 & .000 \\
2 (CSAI-2) & & & \\
The subscale of Cognitive Anxiety & .221 & 144 & .000 \\
The subscale of Somatic Anxiety & .346 & 144 & .000 \\
Subscale of Self-Confidence & -217 & 144 & .000 \\
a. Lilliefors Significance Correction & & & \\
\hline
\end{tabular}


All of the normality test scores indicated that the data were not normal based on the test of Kolmogorov-Smirnov ${ }^{a}(\mathrm{p}<.05)$. Therefore, a nonparametric test; the Kruskal-Wallis test was used to investigate the levels of pre-competition anxiety among the basketball players based on their positions including centre, forward and guard.

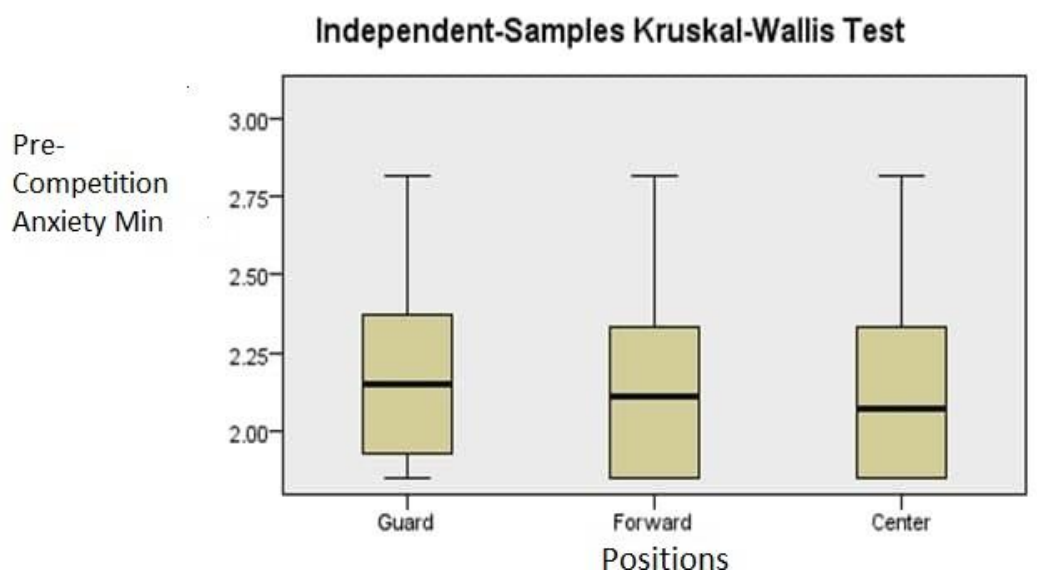

Figure 1: Distribution Plot of Pre-competition Anxiety based on the Players' Positions

Table 3: Kruskal-Wallis Test for Pre-competition Anxiety based on the Players' Positions

\begin{tabular}{cc}
\hline Total $(\mathrm{N})$ & 144 \\
\hline Test Statistic & 3.742 \\
\hline Degrees of Freedom & 2 \\
\hline Asymptotic Sig. (2-sided test) & .154 \\
\hline
\end{tabular}

Table 3 shows the Kruskal-Wallis test results for the research sample $(n=144)$. Figure 1 shows the distribution of scores for the pre-competition anxiety based on the players' positions were not equal; guard (mean rank=80.85), forward players (mean rank=71.50), and centre (mean rank=64.6). Overall analysis showed that the data is not significant, $\chi 2(2)=3.742, p=.154(\mathrm{p}$ > $.05)$. Therefore, it is concluded that there was no difference in pre-competition anxiety scores based on the players' positions as guards, forward and centre players.

Next, the Kruskal-Wallis test was also used to look at the difference in scores for the subscale of cognitive anxiety for centre players, forward players and guards. 


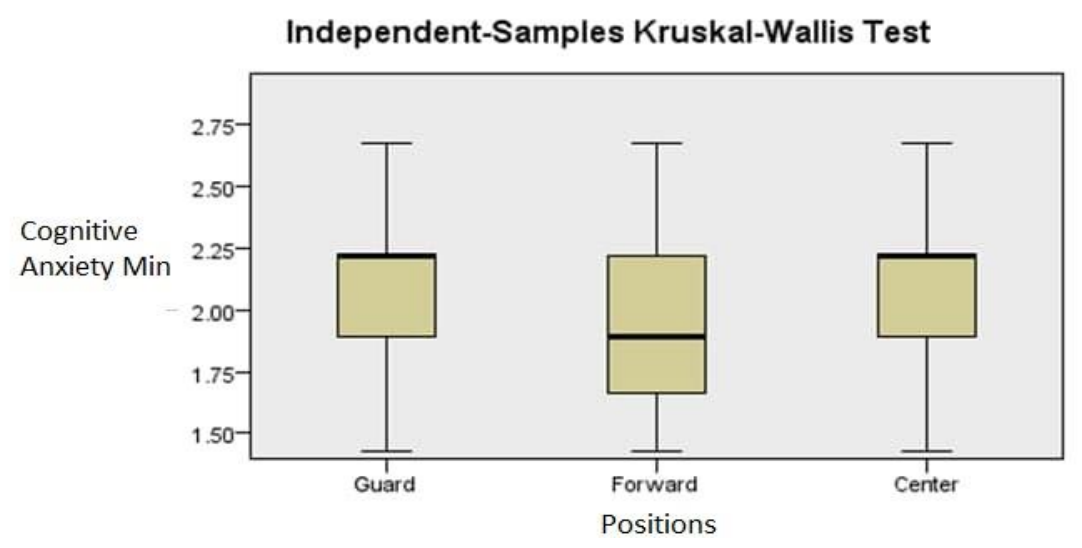

Figure 2: Distribution Plot for Subscale of Cognitive Anxiety based on the Players' Positions

Table 4: Kruskal-Wallis Test for Subscale of Cognitive Anxiety of the Players

\begin{tabular}{cc}
\hline Total $(\mathrm{N})$ & 144 \\
\hline Test Statistic & 1.938 \\
\hline Degrees of Freedom & 2 \\
\hline Asymptotic Sig. (2-sided test) & .380 \\
\hline
\end{tabular}

Table 4 shows the Kruskal-Wallis test for a total of 144 research samples. Meanwhile, Figure 2 shows that the analysis of the Distribution Plot for the subscale of cognitive anxiety is not equal; guards (mean rank=74.52), forward players (mean rank=66.16) and centre players (mean rank=77.10). Overall, the analysis signified that there was no difference in scores for the subscale of cognitive anxiety based on the players' positions as guards, forward and centre players.

The following Kruskal-Wallis test dealt with the subscale of somatic anxiety for the three positions of basketball players, namely guards, forward and centre players. Figure 3 and Table 5 shows the findings:

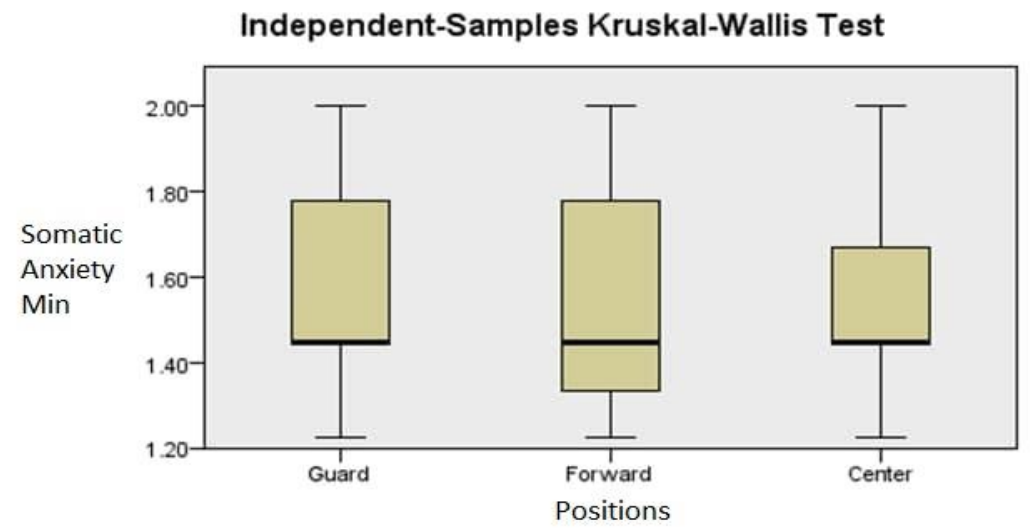

Figure 3: Distribution Plot for the Subscale of Somatic Anxiety based on the Players' Positions 
Table 5: Kruskal-Wallis Test for the Subscale of Somatic Anxiety based on the Players' Positions

\begin{tabular}{cc}
\hline Total $(\mathrm{N})$ & 144 \\
\hline Test Statistic & 1.509 \\
\hline Degrees of Freedom & 2 \\
\hline Asymptotic Sig. (2-sided test) & .470 \\
\hline
\end{tabular}

Based on the table and analysis of the figure, the distribution plot for the subscale of somatic anxiety based on the players' positions is not equal; guards (mean rank=77.71), forward players (mean rank=69.23) and centre players (mean rank=70.42). Overall analysis also showed insignificant value, $\chi 2(2)=1.509, p=.470(\mathrm{p}>.05)$. Therefore, there was no overall difference for the subscale of somatic anxiety based on the players' positions as a guard, forward and centre players in the MSS Sabah basketball tournament.

The final Kruskal-Wallis test dealt with the subscale of self-confidence of the guards, forward and centre players in the basketball tournament. Figure 4 below shows the distribution plot for the subscale of self-confidence for the players while Table 6 shows the Kruskal-Wallis test for the same subscale:

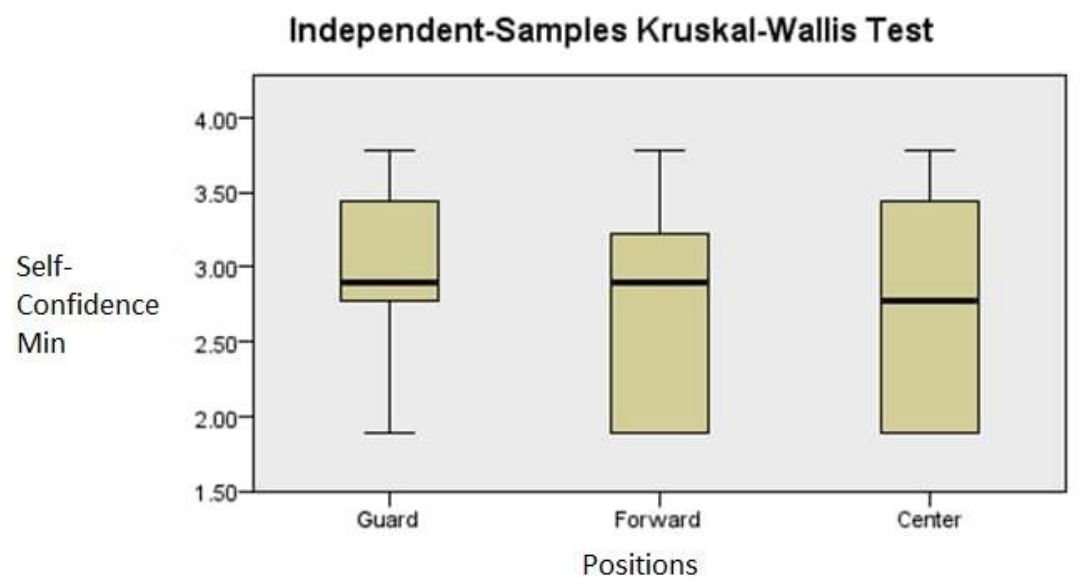

Figure 4: Distribution Plot for the Subscale of Self-Confidence based on the Players' Positions

Table 6: Kruskal-Wallis test for the Subscale of Self-Confidence based on the Players' Positions

\begin{tabular}{cc}
\hline Total $(\mathrm{N})$ & 144 \\
\hline Test Statistic & 1.565 \\
\hline Degrees of Freedom & 2 \\
\hline Asymptotic Sig. (2-sided test) & .457 \\
\hline
\end{tabular}

According to the table and figure which encompasses a total of 144 research samples, the distributions score for the basketball players based on their positions were not equal; guards (mean rank=78.87), forward players (mean rank=72.32) and centre players (mean rank=65.91). 


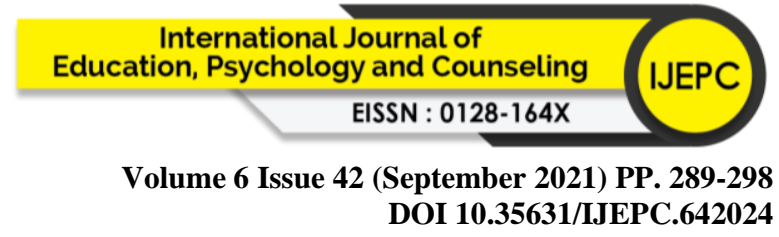

Overall analysis also showed insignificant value of $\chi 2(2)=1.565, p=.457(\mathrm{p}>.05)$. In short, there was no overall difference for the subscale of self-confidence for the players in their respective positions as guards, forward and centre players.

\section{Discussion and Summary}

Based on the findings and analysis, it was summarised that there is no significant difference in the pre-competition anxiety for the subscale of cognitive anxiety, somatic anxiety and selfconfidence among the basketball players at different positions (guard, forward and centre players). Basketball is a group sport that requires strong cohesion between the members in improving the quality of the game, especially in basketball (Esfahani, Soflu, \& Assadi, 2011; Haddera, 2015; Onağ \& Tepeci, 2014). Anxiety among the players playing at different positions either as guards, forward or centre players was observed to be not influencing their pre-competition anxiety because every team members are dependent on each other for support. This is different in comparison to the pre-competition anxiety be it for the subscale of cognitive or somatic anxiety among athletes who play individually such as in the field or racetrack (Nandu \& Noordin, 2020) and tennis (Harris et al., 2021).

The findings are also at par with the research by Mulvenna et al. (2020), which stated that the motivation level of basketball players was high and this could reduce the pre-competition anxiety among the players. Therefore, the positions of players in the basketball sport do not influence their pre-competition anxiety if they have high motivation. Moxley and Towne (2015) also reported in their research that the basketball players observed in their study that the high skills in the game could also lower their pre-competition anxiety. In the context of this research, the positions of players in the game were studied to not correlate with their precompetition anxiety. In the tournament, all the players have to move and play at all the positions, thus they are not subjected to their positions only. This directly indicates that the players' good skills in the game could reduce their pre-competition anxiety.

The analysis of pre-competition anxiety for the subscale of cognitive anxiety showed that there is no significant difference among the basketball players according to their positions. All the players in guards, forward and centre roles did not have high cognitive anxiety. Upon analysing, it was found that the environment, specifically the venue of the tournament, reduced the cognitive anxiety among the players. Many of them had played at the venue several times before, thus they were able to adapt very well. Cognitive anxiety refers to the negative interpretation of the pressures felt by the players in the environment or venue of the tournament. It shows the cognitive interpretation performed by an athlete about the environment before the tournament begins. If the athlete perceives the environment to be detrimental or negative, it will lead to pre-competition anxiety. This is at par with Arruda et al., (2014) who stated that the tournament venue which is new and foreign will increase the pre-competition anxiety level among the basketball players.

As for the subscale of somatic anxiety, the analysis also showed insignificant value among the basketball players based on their positions. Anxiety is a combination of physiological and psychological effects that happen as a result of a player interpreting the situation in a tournament. Somatic anxiety refers to the negative emotional reaction developed as a result of stimulation in the central nervous system, which is out of one's control. It shows indicators such as an increase in pulse, cold sweat, increase in breathing and trembling. Somatic anxiety emerges from physiological changes and environmental pressures developed based on the 


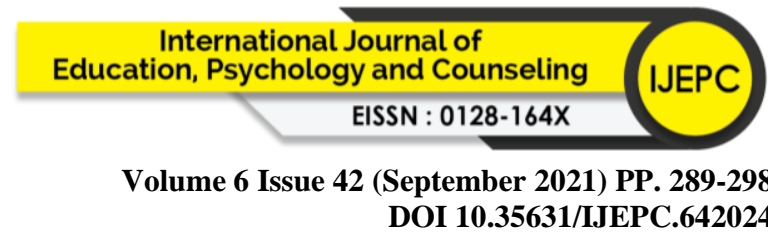

negative interpretation of an athlete. The environmental factors that could reduce the athletes' somatic anxiety include tournaments held at the public hall with a fewer audience and the presence of team members and opposite team members during the tournament. Wright (2015) also stated in his research that the presence of a massive crowd in the audience could increase the pre-competition anxiety among the basketball players.

The last subscale studied in this study was self-confidence, which showed insignificant value among the basketball players based on their positions. The subscale of self-confidence is an important element in improving an athlete's performance and achievement. Self-confidence refers to the level of trust an athlete has towards his or her abilities to compete and achieve success in the competition. Basketball players know each other and their abilities well. They are used to participate in various tournaments organised by the clubs in the districts and other tournaments which gives them enough experience and exposure to their opponents. If the players do not know their opposing team and strengths, it would increase the pre-competition anxiety among the players (Arruda et. al., 2017).

Overall, this study strengthened the views of Vila et al., (2020) who stated that the precompetition anxiety for the subscales of cognitive and somatic anxiety could be reduced if the logistics and environments are well controlled. It amplified that the environmental factors are crucial in balancing the pre-competition anxiety among the basketball players in tournaments. Future studies should be conducted to investigate if the pre-competition anxiety would increase when the players compete at higher levels such as the national level. It would help the coaches and trainers in the Sabah sports school to adopt suitable approaches in dealing with the precompetition anxieties (cognitive, somatic and self-confidence) among the basketball players. Ultimately, it allows the players and teams to achieve more success and compete at higher levels.

\section{References}

Anne Delextrat, D. C., Delextrat, A., \& Cohen, D. (2004). Strength, Power, Speed and Agility of Women Basketball Players According Playing Position. Jornal of Strengh and Conditioning Research, 23(7), 1974-1981. https://doi.org/10.1519/JSC.0b013e3181b86a7e

Aris Fazil Hj Ujang. (2005). Kebimbangan Pra-pertandingan dan Orientasi Matlamat di Kalangan Atlet Merentas Desa. Universiti Putra Malaysia.

Arruda, A. F. S., Aoki, M. S., Paludo, A. C., \& Moreira, A. (2017). Salivary steroid response and competitive anxiety in elite basketball players: Effect of opponent level. Physiology \& Behavior, 177(3), 291-296.

Arruda, A. F. S. S., Aoki, M. S., Freitas, C. G., Drago, G., Oliveira, R., Crewther, B. T., \& Moreira, A. (2014). Influence of competition playing venue on the hormonal responses, state anxiety and perception of effort in elite basketball athletes. Physiology \& Behavior, 130(3), 1-5. https://doi.org/https://doi.org/10.1016/j.physbeh.2014.03.007

Chua Yan Piaw. (2006). Kaedah Penyelidikan. Kuala Lumpur: McGraw-Hill Hill Higher Education.

Cox, R. (2002). Sport psychology: Concepts and application (5 th ed.). Dubuque, IA: WM.C. Brown.

Esfahani, N., Soflu, H. G., \& Assadi, H. (2011). Comparison of Mood in Basketball Players in Iran League 2 and Relation with Team Cohesion and Performance. Procedia - Social 
Volume 6 Issue 42 (September 2021) PP. 289-298

DOI 10.35631/IJEPC.642024

and Behavioral Sciences, 30(4), 2364-2368. https://doi.org/https://doi.org/10.1016/j.sbspro.2011.10.461

Haddera, A. T. (2015). Examing The Relationship Between Team Cohesion, Comparative Anxiety and Self-Confidence Among Ethiopian Basketball Teams. Journal of Tourism, Hospitality and Sports, 13(3), 33-34.

Harris, D. J., Vine, S. J., Eysenck, M. W., \& Wilson, M. R. (2021). Psychological pressure and compounded errors during elite-level tennis. Psychology of Sport and Exercise, 56(3), 101-110. https://doi.org/https://doi.org/10.1016/j.psychsport.2021.101987

He, H., Cui, H., Tang, H., Guo, F., \& Lu, C. (2011). Research on college men's basketball athletes' pre-competition state anxiety and related affecting factors. Chinese Journal of Clinical Psychology, 19(6), 821-823. Retrieved from http://search.ebscohost.com/login.aspx?direct=true\&db=psyh\&AN=2012-05439$032 \&$ site $=$ ehost-live

Martens, R. S. V. dan D. B. (1990). Competitive Anxiety In Sport. Illinois: Human Kinetics Books.

Moxley, J. H., \& Towne, T. J. (2015). Predicting success in the National Basketball Association: Stability \& potential. Psychology of Sport and Exercise, 16, 128-136. https://doi.org/https://doi.org/10.1016/j.psychsport.2014.07.003

Mulvenna, M., Adie, J. W., Sage, L. D., Wilson, N. E., \& Howat, D. (2020). Approachachievement goals and motivational context on psycho-physiological functioning and performance among novice basketball players. Psychology of Sport and Exercise, 51(July), 101714. https://doi.org/10.1016/j.psychsport.2020.101714

Nandu, J., \& Noordin, H. (2020). An Evaluation on the Pre-Competition Anxiety Levels of Under Eighteen Male Track and Field Athletes from the Rural Areas of Sabah. Malaysian Journal of Movement, Health \& Exercise, 9(1), 141-148.

Onağ, Z., \& Tepeci, M. (2014). Team Effectiveness in Sport Teams: The Effects of Team Cohesion, Intra Team Communication and Team Norms on Team Member Satisfaction and Intent to Remain. Procedia - Social and Behavioral Sciences, 150(5), 420-428. https://doi.org/https://doi.org/10.1016/j.sbspro.2014.09.042

Radzi, J. A., Yusuf, S. M., Amir, N. H., \& Mansor, S. H. (2018). Relationship of Precompetition Anxiety and Cortisol Response in Individual and Team Sport Athletes BT - Proceedings of the Second International Conference on the Future of ASEAN (ICoFA) 2017 - Volume 2. In R. Saian \& M. A. Abbas (Eds.) (pp. 719-727). Singapore: Springer Singapore.

Robazza, C., Gallina, S., D’Amico, M. A., Izzicupo, P., Bascelli, A., Di Fonso, A., ... Di Baldassarre, A. (2012). Relationship between biological markers and psychological states in elite basketball players across a competitive season. Psychology of Sport and Exercise, 13(4), 509-517. https://doi.org/10.1016/j.psychsport.2012.02.011

Sekulic, D., Pehar, M., Krolo, A., Spasic, M., Uljevic, O., Calleja-González, J., \& Sattler, T. (2017). Evaluation of basketball-specific agility:applicability of preplanned and nonplanned agility performances for differentiating playing positions and playing levels. Journal of Strength and Conditioning Research, 31(8), 2278-2288. https://doi.org/10.1519/JSC.0000000000001646

Sighinolfi, L. (2020). Sport Psychology in Basketball: Performance Under Pressure BT Basketball Sports Medicine and Science. In L. Laver, B. Kocaoglu, B. Cole, A. J. H. Arundale, J. Bytomski, \& A. Amendola (Eds.) (pp. 983-994). Berlin, Heidelberg: Springer Berlin Heidelberg. https://doi.org/10.1007/978-3-662-61070-1_78 
Smith, R. E., \& Smoll, F. L. (1990). Sport Performance Anxiety BT - Handbook of Social and Evaluation Anxiety. In H. Leitenberg (Ed.) (pp. 417-454). Boston, MA: Springer US. https://doi.org/10.1007/978-1-4899-2504-6_14

Vila, G. O., Rodríguez, J. R., Fuentes-Guerra, F. J. G., Martín, J. F., Sánchez, A. C. J., González, L. J. D., ... Abad Robles, M. T. (2020). Competitive anxiety in young basketball players from the real madrid foundation. Sustainability, 12(9), 120-131. https://doi.org/10.3390/SU12093596

Wright, J. L. (2015). The relationship between live crowds, competitive anxiety, and performance for high school basketball players. Sport and Exercise Psychology, 3(2), $111-122$. 